\begin{tabular}{|c|c|c|c|}
\hline Case Reports in & \multicolumn{2}{|c|}{ Case Rep Gastroenterol 2020;14:248-254 } & \multirow[b]{2}{*}{$\begin{array}{l}\text { Karger } \\
\text { Open'access }\end{array}$} \\
\hline Gastroenterology & $\begin{array}{l}\text { DOI: } 10.1159 / 000507076 \\
\text { Published online: April 29, } 2020\end{array}$ & $\begin{array}{l}\text { () } 2020 \text { The Author(s) } \\
\text { Published by S. Karger AG, Basel } \\
\text { www.karger.com/crg }\end{array}$ & \\
\hline & $\begin{array}{l}\text { This article is licensed under } \\
\text { International License (CC BY-N } \\
\text { Usage and distribution for comm }\end{array}$ & $\begin{array}{l}\text { nons Attribution-NonCommercic } \\
\text { ger.com/Services/OpenAccessLic } \\
\text { uires written permission. }\end{array}$ & \\
\hline
\end{tabular}

\title{
Ultimate Stomaless Technique of Two- Stage Operation for Lower Rectal Cancer Performed on a Patient with a High Body Mass Index: The Reborn Operation (Novel Pull-Through Method)
}

\author{
Toshikatsu Nitta ${ }^{a, b} \quad$ Keitaro Tanaka ${ }^{a, b}$ Jun Kataoka ${ }^{a, b} \quad$ Masato Ohta, \\ Masatsugu Ishii ${ }^{a, b}$ Takashi Ishibashi ${ }^{a}$ b Junji Okuda ${ }^{a, b}$ \\ aDivision of Surgery, Gastroenterological Center, Medico Shunju Shiroyama Hospital, \\ Osaka, Japan; bepartment of Colorectal Surgery, Osaka Medical College, Osaka, Japan
}

\section{Keywords}

Lower rectal cancer - High body mass index - Indocyanine green fluorescence imaging .

Stomaless surgery $\cdot$ Pull-through procedure

\begin{abstract}
A 58-year-old Japanese man, with a body mass index of $41.7 \mathrm{~kg} / \mathrm{m}^{2}$ (height: $179.8 \mathrm{~cm}$; weight: $133.8 \mathrm{~kg}$ ), underwent a laparoscopic pull-through procedure with delayed coloanal anastomosis performed in two surgical stages for lower rectal cancer. This method was selected because the volume of the abdominal wall was fairly thick and it would have been impossible to perform diverting ileostomy and colostomy, which are routinely conducted. First, a colonic pull-through segment of about $10 \mathrm{~cm}$ was left outside the anal canal without any tension and was fixed by sutures under indocyanine green fluorescence imaging (ICG FI). The second surgical stage was performed 10 days after the first operation under general anesthesia. Final coloanal anastomosis was performed with near-infrared light without diverting the stoma under ICG FI. The patient demonstrated a good postoperative course and was discharged from our hospital in remission 15 days after the latest operation. We could inspect the coloanal flow of the anastomosis under ICG FI before the reconstruction. This procedure was considered to be a
\end{abstract}




\section{Case Reports in Gastroenterology}

Case Rep Gastroenterol 2020;14:248-254 DOI: $10.1159 / 000507076$

(c) 2020 The Author(s). Published by S. Karger AG, Basel www.karger.com/crg

Nitta et al.: The Reborn Operation: Novel Pull-Through Technique

standard method, but it was overtaken by new technology, ICG FI. This procedure is an ultimate stomaless surgery for ultralow rectal cancer that can be performed in selected cases, such as in patients with a high body mass index and with hope for stomaless operation.

(C) 2020 The Author(s)

Published by S. Karger AG, Basel

\section{Introduction}

Recently, the prevalence of lower rectal cancer has increased worldwide. For successful surgical treatment, it is important to maintain the circumferential resection margins and meticulously perform transanal total mesorectal excision (TaTME) or robotic resection. Robotassisted low rectal surgery and TaTME have been developed as options to retain the circumferential resection margins during total mesorectal excision [1]. Specifically, TaTME is one of the best procedures performed in demanding cases, such as in patients presenting a narrow pelvis.

The weakness of the TaTME method for lower rectal cancer treatment is the appearance of colon anastomotic leakage and pelvic sepsis events, which occur in $4-20 \%$ of cases [2]. Moreover, complications related to low rectal anastomosis are reported to amount to approximately $11 \%$ even in cases of diverting ileostomy creation [3]. There are some issues with stomata even when the diverting ileostomy is created to avoid the anastomotic leakage resulting from low rectal cancer. Diverting ileostomy-related morbidity rates are still nonnegligible, especially in challenging cases [4].

Here, we introduce our surgical technique, i.e., a stomaless pull-though procedure with a two-stage operation for lower rectal cancer treatment, performed on a patient with a high body mass index (BMI) who was a former sumo wrestler.

\section{Case Presentation}

A 58-year-old Japanese man was suffering from discomfort with left lower abdominal pain and visited our hospital. The patient's BMI was calculated as $41.7 \mathrm{~kg} / \mathrm{m}^{2}$ (height: 179.8 cm; weight: $133.8 \mathrm{~kg}$ ).

A total colonoscopy revealed a lesion in the rectum below the peritoneal reflection $(4 \mathrm{~cm}$ above the anal verge) (Fig. 1). The laboratory findings at the time of admission were within normal limits including tumor marker levels.

The patient was subsequently scheduled for laparoscopic intersphincteric resection via the transanal approach for early rectal cancer. The pull-through procedure with delayed coloanal anastomosis was performed in two surgical stages. Preoperatively, the patient underwent nutrition management for 3 months, and his BMI decreased to $34.3 \mathrm{~kg} / \mathrm{m}^{2}$ (height: 177.4 cm; weight: $108.0 \mathrm{~kg}$ ) (Fig. 2).

In the first stage of the abdominal phase, the patient was placed in the lithotomy position. High ligation of the inferior mesenteric artery and vein was performed. The left colon was fully mobilized and brought down and reached the anal verge without tension. In the perineal phase, a Lone Star self-retaining retractor (Lone Star Medical Products, Inc, Houston, TX, USA) was placed at the anus, a purse-string suture was placed approximately $1 \mathrm{~cm}$ from the anal verge, and circumferential dissection was performed $1 \mathrm{~cm}$ from the purse-string suture. The AirSeal System (SurgiQuest Inc, Milford, CT, USA) was used to perform the TaTME after the 
GelPOINT (Applied Medical Resources Corporation, Rancho Santa Margarita, CA, USA) access system was set up.

Before that surgery, a urethral catheter with a guide wire was inserted into the urethra under fluoroscopic guidance, after the infrared illumination system urethral kit (IRIS U kit) was used [5]. Near-infrared light was used to increase visibility when using the laparoscopic system (1588 AIM ${ }^{\mathrm{TM}}$; Stryker) during the laparoscopic and TaTME stages of the procedure. The patient recovered uneventfully without urethral injury.

A colonic pull-through segment of about $10 \mathrm{~cm}$ was left outside the anal canal without any tension and fixed by sutures under indocyanine green fluorescence imaging (ICG FI) (Fig. 3). The prostatic segment of the urethra was easily and quickly identified with the green fluorescence during TaTME. The first total operation time was $435 \mathrm{~min}$, including a perineal phase of $122 \mathrm{~min}$, and the intraoperative blood loss was $65 \mathrm{~mL}$.

The second surgical stage was performed 10 days after the first operation under general anesthesia. The patient was placed in the lithotomy position and a Lone Star retractor was positioned. The adhesion was fully detached at the anal canal. Final coloanal anastomosis was performed using near-infrared light. It was sutured using 16 interrupted absorbable sutures without diverting the stoma under ICG FI (Fig. 4).

The second total operative time was $111 \mathrm{~min}$, and the intraoperative blood loss was 118 $\mathrm{mL}$. The patient demonstrated a good postoperative course and he was discharged from our hospital in remission 15 days after the latest operation.

In this way, we managed to perform a pull-though procedure with a two-stage operation for a case of lower rectal cancer in a patient with a high BMI.

\section{Discussion}

The transanal pull-through procedure was an anus-preserving operation first introduced by Babcock [6] in 1932. However, pull-through followed by delayed coloanal anastomosis has nowadays been reported by only a few centers in France and the Cleveland Clinic in the USA $[7,8]$.

The two-stage Turnbull-Cutait coloanal anastomosis is considered to be an effective alternative surgical method in the current approach to low rectal cancer treatment without the need of a temporary diverting stoma, preventing a wide range of complications related to stoma surgery [9].

Turnbull and Cuthbertson [10] at the Cleveland Clinic developed a surgical technique of two-stage transanal anastomosis to avoid a permanent colostomy. Besides, Cutait and Figliolini [11] performed the same technique in two stages in the same year (1952) in Brazil. Thus, the pull-through procedure was traditionally performed in two stages with resection of the tumor and exteriorization of the proximal colon through the anus during the first stage, followed by delayed coloanal anastomosis several days later, avoiding stoma protection [9-11]. However, the pull-through procedure has gradually become disused due to the need for a twostage operation and the existence of complications with anastomotic leakage and stricture. As a result, most surgeons create a temporary stoma.

The creation of diverting ileostomy is assumed to reduce the risks of anastomotic dehiscence complications, especially anastomotic leakage, according to a meta-analysis by Tan et al. [12]. That is why we routinely perform a diverting ileostomy in almost all patients undergoing sphincter-saving rectal resection with coloanal anastomosis including TaTME [13-15] to decrease the rate of anastomotic leakage. 
However, there are many reports regarding stoma-related morbidities that are called "stoma complications" [16]. Stoma complications consist of two types: early and late stoma complications, which are both based on surgical procedures [17]. There are several early stoma complications, such as mucocutaneous separation, stoma retraction, stoma necrosis, stoma site infection, and stoma obstruction including stoma outlet obstruction, fistula, bleeding, and trauma. Their occurrence is due to patient-related factors, especially obesity, i.e., a high BMI [16-19]. In this case, the patient's BMI was $41.7 \mathrm{~kg} / \mathrm{m}^{2}$ (height: $179.8 \mathrm{~cm}$; weight: $133.8 \mathrm{~kg}$ ) and the volume of the abdominal wall was fairly thick, as revealed by computed tomography (Fig. 2).

We considered that it would be impossible to perform the diverting ileostomy and colostomy even if the stoma was of the single- or double-barrel type in this case. This is why we selected the laparoscopic pull-through method for low rectal cancer treatment, with which no stoma surgery is needed.

Nowadays, this two-stage pull-through technique has been reintroduced to prevent the construction of a permanent stoma [4, 9, 20, 21]. In the study by Jarry et al. [22], the rate of anastomotic leakage and pelvic abscess was 2 and 6\%, respectively, which are both acceptable results. That is why this technique would be an effective surgical alternative procedure in selected cases [9]. Besides, anastomotic leakage and stricture were based on the coloanal flow of the anastomosis. Thus, we could inspect the coloanal flow of the anastomosis under ICG FI before reconstruction, which is the end point of the first and the start of the second operation. Therefore, it might be possible to perform the pull-through procedure without anastomotic leakage and stricture under ICG FI.

ICG fluorescence angiography leads to significantly increased changes in the resection line and is a promising optical imaging technique to reduce anastomotic leakage [23]. This procedure was considered to be a standard method; however, it was overtaken by a new technology, namely, ICG FI. This procedure introduces an ultimate stomaless surgery for ultralow rectal cancer, which can be performed in selected cases, such as on patients with a high BMI and with hope for stomaless operation.

\section{Acknowledgements}

The authors wish to thank K. Koyama, MD, PhD, from the Department of Urology, Medico Shunju Shiroyama Hospital, Osaka, Japan.

\section{Statement of Ethics}

Ethics committee approval was not necessary for this paper, because this paper just covers a surgical technique. Informed consent was obtained from the patient.

\section{Disclosure Statement}

The authors declare that there are no conflicts of interests. 


\section{Funding Sources}

No specific funding was received for the present analysis.

\section{Author Contributions}

Toshikatsu Nitta wrote the paper and all authors contributed to the medical treatment.

\section{References}

1 Heald RJ, Moran BJ, Ryall RD, Sexton R, MacFarlane JK. Rectal cancer: the Basingstoke experience of total mesorectal excision, 1978-1997. Arch Surg. 1998 Aug;133(8):894-9.

2 Nesbakken A, Nygaard K, Lunde OC. Outcome and late functional results after anastomotic leakage following mesorectal excision for rectal cancer. Br J Surg. 2001 Mar;88(3):400-4.

3 Paun BC, Cassie S, MacLean AR, Dixon E, Buie WD. Postoperative complications following surgery for rectal cancer. Ann Surg. 2010 May;251(5):807-18.

4 Bianco F, Belli A, De Franciscis S, Falato A, Romano GM. "Scarless" and no-stoma surgery for low rectal cancer: the laparoscopic pull-through delayed "high" colo-anal anastomosis. Updates Surg. 2016 Mar;68(1):99-104.

5 Nitta T, Tanaka K, Kataoka J, Ohta M, Ishii M, Ishibashi T, et al. Novel technique with the IRIS U kit to prevent urethral injury in patients undergoing transanal total mesorectal excision. Ann Med Surg (Lond). 2019 Aug;46:1-3.

6 Babcock WW. William Wayne Babcock 1872-1963. The operative treatment of carcinoma of the rectosigmoid with methods for the elimination of colostomy. Dis Colon Rectum. 1989 May;32(5):442-7.

7 Hallet J, Milot H, Drolet S, Desrosiers E, Grégoire RC, Bouchard A. The clinical results of the Turnbull-Cutait delayed coloanal anastomosis: a systematic review. Tech Coloproctol. 2014 Jun;18(6):579-90.

8 Hallet J, Bouchard A, Drolet S, Milot H, Desrosiers E, Lebrun A, et al. Anastomotic salvage after rectal cancer resection using the Turnbull-Cutait delayed anastomosis. Can J Surg. 2014 Dec;57(6):405-11.

9 Biondo S, Trenti L, Galvez A, Espin-Basany E, Bianco F, Romano G, et al.; Turnbull-BCN study group. Twostage Turnbull-Cutait pull-through coloanal anastomosis versus coloanal anastomosis with protective loop ileostomy for low rectal cancer. Protocol for a randomized controlled trial (Turnbull-BCN). Int J Colorectal Dis. 2017 Sep;32(9):1357-62.

10 Turnbull RB Jr, Cuthbertson A. Abdominorectal pull-through resection for cancer and for Hirschsprung's disease. Delayed posterior colorectal anastomosis. Cleve Clin Q. 1961 Apr;28(2):109-15.

11 Cutait DE, Figliolini FJ. A new method of colorectal anastomosis in abdominoperineal resection. Dis Colon Rectum. 1961 Sep-Oct;4(5):335-42.

12 Tan WS, Tang CL, Shi L, Eu KW. Meta-analysis of defunctioning stomas in low anterior resection for rectal cancer. Br J Surg. 2009 May;96(5):462-72.

13 Matthiessen P, Hallböök O, Rutegård J, Simert G, Sjödahl R. Defunctioning stoma reduces symptomatic anastomotic leakage after low anterior resection of the rectum for cancer: a randomized multicenter trial. Ann Surg. 2007 Aug;246(2):207-14.

14 Montedori A, Cirocchi R, Farinella E, Sciannameo F, Abraha I. Covering ileo- or colostomy in anterior resection for rectal carcinoma. Cochrane Database Syst Rev. 2010 May;(5):CD006878.

15 Hain E, Maggiori L, Manceau G, Zappa M, Prost à la Denise J, Panis Y. Persistent asymptomatic anastomotic leakage after laparoscopic sphincter-saving surgery for rectal cancer: can diverting stoma be reversed safely at 6 months? Dis Colon Rectum. 2016 May;59(5):369-76.

16 Porter JA, Salvati EP, Rubin RJ, Eisenstat TE. Complications of colostomies. Dis Colon Rectum. 1989 Apr;32(4):299-303.

17 Cottam J, Richards K, Hasted A, Blackman A. Results of a nationwide prospective audit of stoma complications within 3 weeks of surgery. Colorectal Dis. 2007 Nov;9(9):834-8.

18 Kann BR. Early stomal complications. Clin Colon Rectal Surg. 2008 Feb;21(1):23-30.

19 Parmar KL, Zammit M, Smith A, Kenyon D, Lees NP; Greater Manchester and Cheshire Colorectal Cancer Network. A prospective audit of early stoma complications in colorectal cancer treatment throughout the Greater Manchester and Cheshire colorectal cancer network. Colorectal Dis. 2011 Aug;13(8):935-8.

20 Xiong Y, Huang P, Ren QG. Transanal pull-through procedure with delayed versus immediate coloanal anastomosis for anus-preserving curative resection of lower rectal cancer: a case-control study. Am Surg. 2016 Jun;82(6):533-9. 
Nitta et al.: The Reborn Operation: Novel Pull-Through Technique

21 Patsouras D, Yassin NA, Phillips RK. Clinical outcomes of colo-anal pull-through procedure for complex rectal conditions. Colorectal Dis. 2014 Apr;16(4):253-8.

22 Jarry J, Faucheron JL, Moreno W, Bellera CA, Evrard S. Delayed colo-anal anastomosis is an alternative to prophylactic diverting stoma after total mesorectal excision for middle and low rectal carcinomas. Eur J Surg Oncol. $2011 \mathrm{Feb}$;37(2):127-33.

23 Morales-Conde S, Alarcón I, Yang T, Licardie E, Camacho V, Aguilar Del Castillo F, et al. Fluorescence angiography with indocyanine green (ICG) to evaluate anastomosis in colorectal surgery: where does it have more value? Surg Endosc. 2019 [Epub ahead of print]

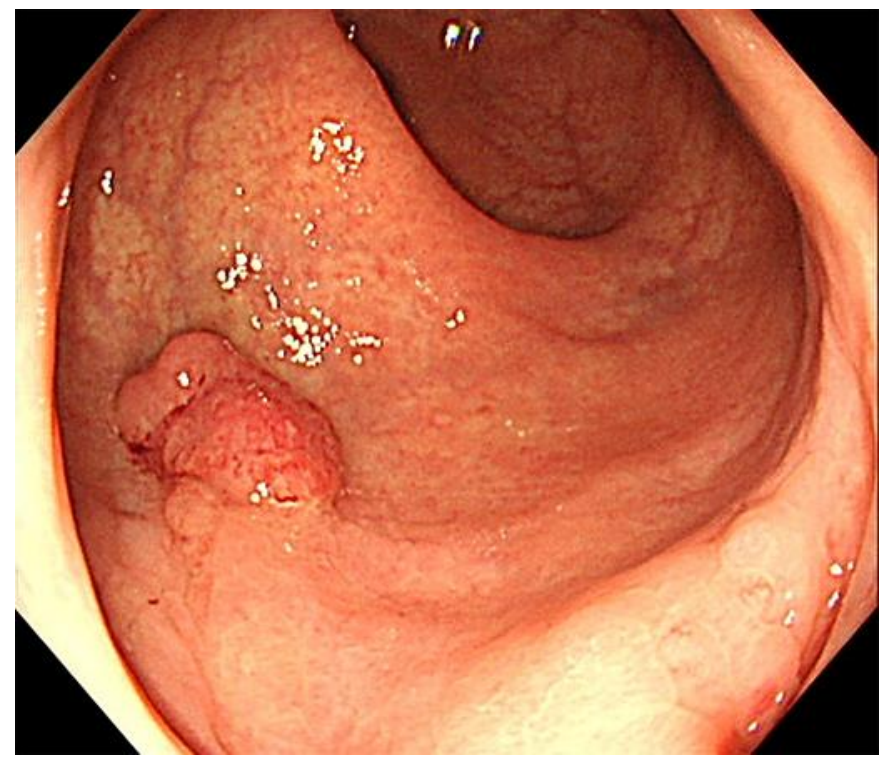

Fig. 1. Total colonoscopy revealed a lesion in the rectum below the peritoneal reflection $(4 \mathrm{~cm}$ above the anal verge).
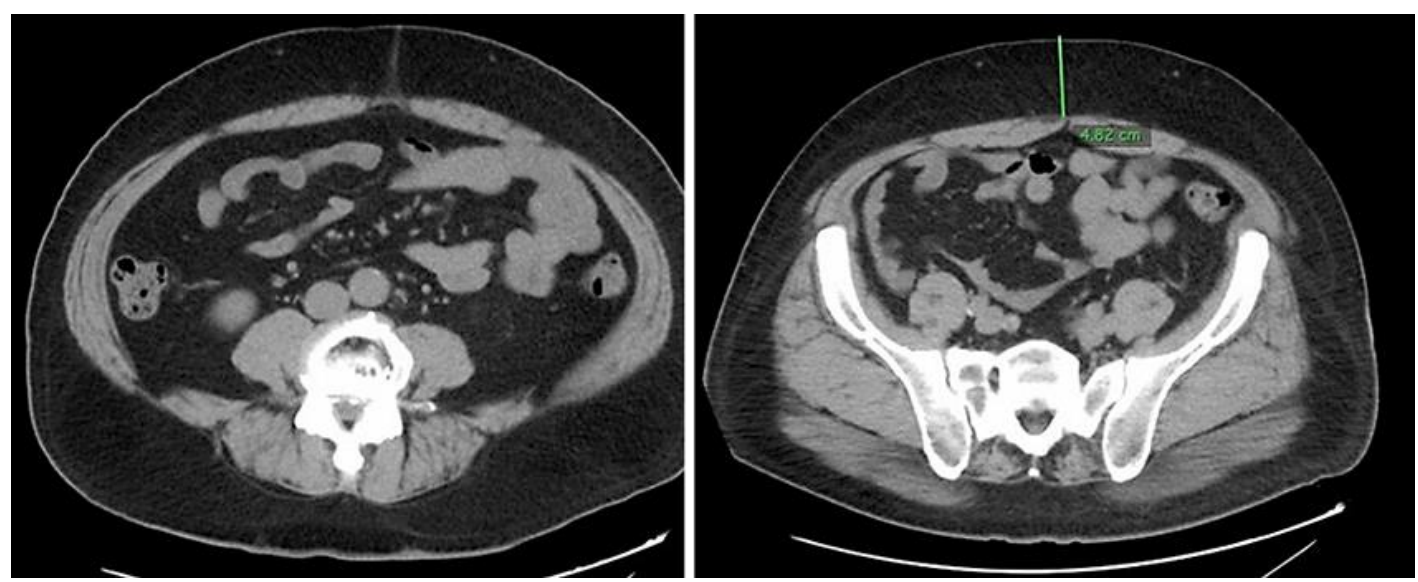

Fig. 2. Computed tomography images. The patient's body mass index had decreased from $41.7 \mathrm{~kg} / \mathrm{m}^{2}$ (height: $179.8 \mathrm{~cm}$; weight: $133.8 \mathrm{~kg}$ ) to $34.3 \mathrm{~kg} / \mathrm{m}^{2}$ (height: $177.4 \mathrm{~cm}$; weight: $108.0 \mathrm{~kg}$ ). 


\section{Case Reports in Gastroenterology}

\begin{tabular}{l|l}
\hline Case Rep Gastroenterol 2020;14:248-254 \\
\hline DOI: 10.1159/000507076 & $\begin{array}{l}\text { c 2020 The Author(s). Published by S. Karger AG, Basel } \\
\text { www.karger.com/crg }\end{array}$ \\
\hline
\end{tabular}

Nitta et al.: The Reborn Operation: Novel Pull-Through Technique

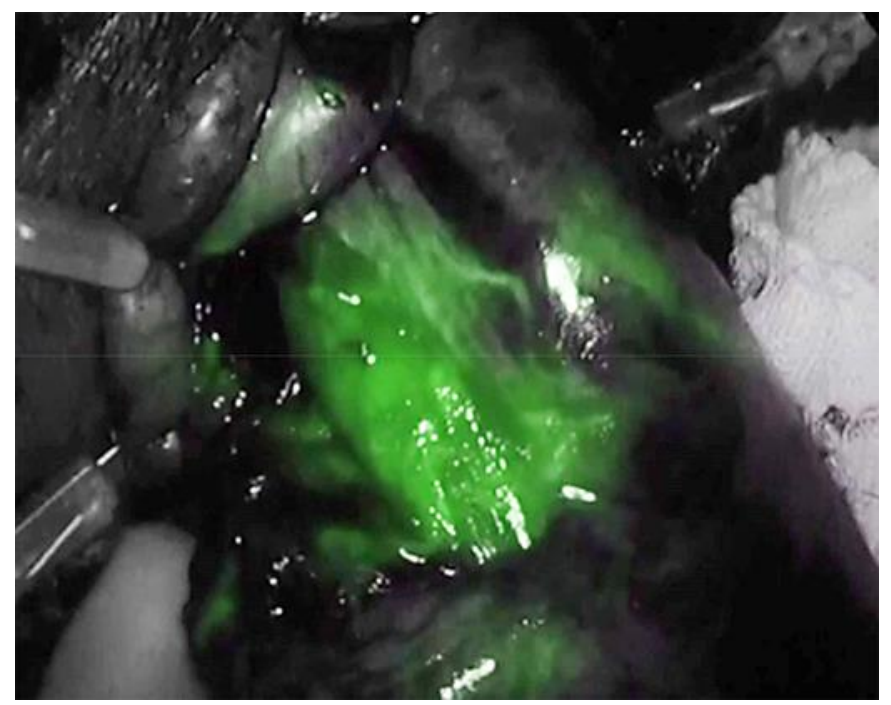

Fig. 3. A colonic pull-through segment of about $10 \mathrm{~cm}$ was left outside the anal canal without any tension and was fixed by sutures under indocyanine green fluorescence imaging.

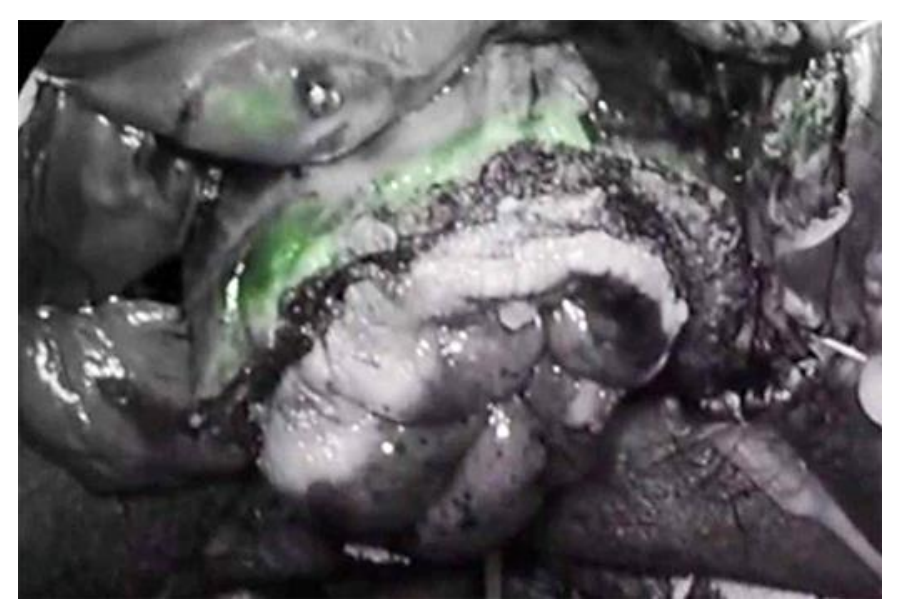

Fig. 4. Final coloanal anastomosis was performed without diverting the stoma under indocyanine green fluorescence imaging. 